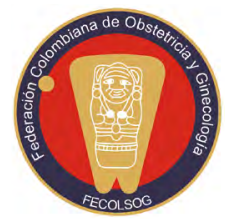

\title{
TRANSMISIÓN PERINATAL DE SARS-COV-2: NECESIDAD DE ESTUDIO ANTE POSIBLE INFECCIÓN CONGÉNITA
}

\author{
Perinatal transmission of SARS-CoV-2: Need of \\ study by possible congenital infection \\ Oscar Limay-Ríos, $\mathrm{PhD}^{1}$; Carmen Dávila-Aliaga, $\mathrm{MD}^{2}$; \\ Ricardo Álvarez-Carrasco $\mathrm{MD}^{3}$; Marcos Espinola-Sánchez $\mathrm{MSc}^{4}$
}

05 de septiembre de 2020

\section{Sr. Editor.}

La infección por SARS-CoV-2, se propaga rápidamente en la población. Los reportes hasta el momento en gestantes muestran un compromiso clínico similar a la población general, en su mayoría asintomática u oligosintomática (1). No hay evidencia definitiva sobre la transmisión transplacentaria de este virus; sin embargo, se han publicado reportes sobre la presencia de anticuerpos IgM elevados en el recién nacido, en las primeras horas posparto, lo que podría indicar que es posible la transmisión vertical del SARS-CoV-2 (2).

El Instituto Nacional Materno Perinatal (INMP) tiene nivel III-2 que, dentro de la organización sa-

* Correspondencia: Marcos Espinola Sánchez Jr., Santa Rosa, 941, Cercado de Lima (Perú). marcosespinola.es@gmail.com

1 Médico ginecobstetra; doctor en Medicina, Universidad Nacional Mayor de San Marcos. Lima (Perú).

2 Médico especialista en Neonatología, Instituto Nacional Materno Perinatal; Universidad Nacional Federico Villarreal. Lima (Perú).

3 Médico especialista en Patología clínica, Instituto Nacional Materno Perinatal. Lima (Perú).

4 Médico cirujano; magíster en Ciencias en Investigación Clínica, Instituto Nacional Materno Perinatal. Universidad Privada del Norte. Lima (Perú). nitaria nacional de Perú, corresponde al centro de referencia nacional en salud materna y perinatal, en donde se atienden alrededor de 18 mil partos al año. Actualmente, debido a la pandemia por el virus SARS-CoV-2, el INMP realiza la prueba serológica a las gestantes que se hospitalizan para la atención de parto. Todo neonato cuya madre presenta un resultado de prueba serológica positiva, se somete a prueba serológica rápida para medir $\operatorname{IgM}$ e $\operatorname{IgG}$, y a la prueba de reacción en cadena de polimerasa con transcriptasa inversa (RT-PCR), a partir de la toma de muestra de hisopado nasofaríngeo, procesada en el Instituto Nacional de Salud de Perú.

La prueba serológica empleada en el INMP -One Step Test Kit Covid-19-, certificada por la Comunidad Europea, tiene una sensibilidad de $94 \%$ para la IgM y una especificidad de $100 \%$; para la IgG la sensibilidad es de $94 \%$ y especificidad de $100 \%$, y para la detección de ambas Ig la sensibilidad es de 97,6\% y especificidad de $100 \%$, según especificaciones registradas en el inserto de la prueba (3). Comparado con la prueba de RT-PCR, la prueba de detección de anticuerpos combinados de inmunoglobulinas $\operatorname{IgG}$ e IgM presenta buena sensibilidad (entre 87-88\%) y especificidad (entre 90-100\%) para el diagnóstico para SARSCoV-2 (4). 
Durante el mes de abril 2020, se registraron 47 muestras de hisopado nasofaríngeo en neonatos, de hasta dos días de nacidos, cuyos resultados fueron negativos, a excepción de un caso cuya muestra fue tomada al segundo día de vida, sin poder descartar una posible infección congénita, intraparto o posnatal. El caso del recién nacido con prueba molecular positiva presentó prueba serológica negativa para la infección por el SARS-CoV-2; mientras que, de los 46 recién nacidos con prueba molecular negativa, 17 presentaron anticuerpos de IgM positiva/IgG positiva y 5 presentaron solamente $\operatorname{IgG}$ positiva.

Dado que la IgM es una macromolécula, la cual no atraviesa regularmente la placenta (5), se trataría de una respuesta neonatal, la cual podría corresponder a una infección congénita; sin embargo, debido a que la determinación de anticuerpos es por prueba rápida, es posible dar falsos positivos por otros virus y otras moléculas como hormonas; además, por ser un ensayo indirecto cualitativo no puede ser concluyente en el diagnóstico de una infección congénita (5-7). No obstante, existen investigaciones que indican posible infección transplacentaria $(8,9)$.

Teorizando a partir de los hallazgos observados, y ante una posible transmisión congénita, la prueba RTPCR que se efectuó en neonatos a partir de muestras nasofaríngeas es posible que presente limitaciones para detectar el virus SARS-Cov-2, debido a la toma misma de la muestra, la duración de la viremia desde el momento de la posible infección intraútero, carga viral y tiempo en los tejidos del tracto respiratorio superior, lo cual podría contrastar con identificación del virus en tejidos de la placenta, cordón umbilical, líquido amniótico, sangre, secreción alveolar y heces del neonato. Actualmente, la disponibilidad de exámenes diagnósticos en los tejidos mencionados es escasa.

A pesar de que se han observado casos de neonatos con la presencia de IgM contra SARS-CoV-2, no es posible afirmar la existencia de una infección congénita basada solo con la detección de $\operatorname{IgM}$, por lo que se requieren más estudios a partir de muestras de líquido amniótico, cordón umbilical o placenta.

\section{REFERENCIAS}

1. Sutton D, Fuchs K, D'Alton M, Goffman D. Universal Screening for SARS-CoV-2 in Women Admitted for Delivery. NEJM. 2020;382:2163-4. https://doi. org/10.1056/NEJMc2009316.

2. Puopolo K, Hudak M, Kimberlin D, Cummings J. Initial Guidance: Management of Infants Born to Mothers with COVID-19. American Academy of Pediatrics Committee on Fetus and Newborn, Section on Neonatal Perinatal Medicine, and Committee on Infectious Diseases; 2020. Disponible en: https:// downloads.aap.org/AAP/PDF/COVID\%2019\%20 Initial\%20Newborn\%20Guidance.pdf

3. One Step Test Kit. Core Technology Co. Limited. Pekín, República Popular China; 2020.

4. Aramburu A. Precisión diagnóstica de pruebas rápidas de detección de anticuerpos para SARS-CoV-2. Serie Revisiones Rápidas No 01-2020. Lima: Unidad de Análisis y Generación de Evidencias en Salud Pública, Instituto Nacional de Salud; 2020. Disponible en: https://web.ins.gob.pe/sites/default/files/Archivos/ authenticated $\% 2 \mathrm{C} \% 20$ administrator\%2 C\%20 editor/publicaciones/2020-04-15/RR\%2001\%20 Pruebas\%20rapidas\%20SARS-CoV-2\%20-\%20 Serolog\%C3\%ADa_V.02_final.pdf

5. Dong L, Tian J, He S, Zhu C, Wang J, Liu C, et al. Possible vertical transmission of SARS-CoV-2 from an infected mother to her newborn. JAMA. 2020;323(18):1846-8. https://doi.org/10.1001/jama.2020.4621.

6. Hosier H, Farhadian S, Morotti R, Deshmukh U, LuCulligans A, Campbell K, et al. First case of placental infection with SARS-CoV-2. BMJ. 2020. https://doi. org/10.1101/2020.04.30.20083907.

7. Penfield CA, Brubaker S, Limaye M, Lighter J, Ratner A, Thomas KM, et al. Detection of sars cov 2 in placental and fetal membrane samples. Am J Obstet Gynecol MFM. 2020; 2(3):100133. https://doi. org/10.1016/j.ajogmf. 2020.100133

8. Cruz AT, Zeichner SL. COVID-19 in Children: Initial characterization of the pediatric disease. Pediatrics. 2020;145(6):e20200834. https://doi.org/10.1542/ peds.2020-0834. 
9. Chen H, Guo J, Wang C, Luo F, Yu X, Zhang W, et al. Clinical characteristics and intrauterine vertical transmission potential of COVID-19 infection in nine pregnant women: A retrospective review of medical records. Lancet. 2020;395(10226):809-15. https:// doi.org/10.1016/S0140-6736(20)30360-3

Conflicto de intereses: ninguno declarado. 